\title{
EDITORLAL
}

\section{Forensic Dentistry for Sri Lanka : Assisting its birth and life supporting its future trajectories}

Forensic dentistry or forensic odontology is a highly specialized branch in dentistry which deals with proper handling, investigating and examining oro facial evidence for medico legal purposes. Further, it involves evaluation and interpreting oro facial evidence and provision of expert opinions in the interest of justice.

Historically, and at present, forensic dentistry has played a major role in crime investigations and human identification. There are evidence in the history that goes as far back as $\mathrm{AD}$ 49, where dental evidence have been used to identify victims (Lollia and Agrapinna incident). Further, Paris bazaar fire (1897) Pijama Girl Case 1934, Ruxton murder case 1935, Haigh acid bath murder and Ted Bundy cases are remarkable historical criminal cases where forensic dentistry was significantly used in the administration of justice. As per recent examples Lokerbie Air disaster, Katrina, 9/11 blast, London Bombing and Tsunami are significant.

The role of a forensic odontologist (a practitioner of forensic dentistry) includes the identification of the unknown, provision of expertise at a scene of crime or mass disaster, age estimations of both living and deceased persons including neo-natal remains, the analysis of bite marks found on victims of attack or on other substances, medico legal examination and interpreting dental and oro-facial injuries, expert testimony, lip print analysis, expert opinions on dental fraud, dental negligence, ethics and malpractice, to name a few.

Currently, forensic dentistry is a well established clinical/ academic specialty worldwide. However, in Sri Lanka, this important discipline is in its infancy or rather in its fetal stages. Only a very basic aspect of forensic dentistry is taught in the undergraduate dental curriculum in Sri Lanka at the one and only dental school in the country and this exposure is not at all sufficient to practice forensic dentistry effectively.

Unfortunately, so far, there is no post graduate training in forensic dentistry in Sri Lanka.

At present there are only a very few dental officers (including myself) who practice forensic dentistry in the entire country. Therefore for those of us who practice forensic dentistry in Sri Lanka had to invariably expose ourselves to foreign training to update/upgrade our knowledge and skills in modern forensic dentistry.

There is a growing demand and an interest in this discipline (forensic dentistry) among dental students, dental practitioners and other stake holders including police courts and criminal justice system which warrant a structured quality post graduate training program in forensic dentistry.

The importance of forensic dentistry has been discussed at many forums in Sri Lanka but unfortunately until recently not much has been done for this important discipline for numerous reasons.

I have been involved in teaching and examining forensic dentistry in Sri Lanka at national level (in addition to providing forensic service function) at the faculty of Dental Sciences (the one and only dental school in Sri Lanka) since 1998 - over 13 years continuously and consecutively. I was able to introduce and revise the curriculum in forensic odontology in the dental curriculum, to suit the current needs and secure a separate forensic odontology module/ unit under oral pathology in the 
final year in the new dental curriculum. However this limited hours of learning with no practical exposure is not at all sufficient for effective and quality forensic practice. I was able to propose a further developed forensic odontology curriculum with some basic practical training for the proposed five year undergraduate dental curriculum revision in Sri Lanka. But this nation requires a quality post graduate training in forensic dentistry in the name of professional development, research, team work, service function and justice.

On an invitation by the Faculty of Dental Sciences at University of Peradeniya, I designed and prepared a masters degree level taught course in forensic dentistry to be offered via the faculty of Dental Sciences which was unanimously approved by the faculty board of dental sciences and university. Although this degree is a masters degree, the graduates of this proposed masters degree will not be considered specialists in the health ministry set up (or in military service) as the only qualification recognized by the ministry of heath as a specialist qualification are those qualifications earned through the PGIM (Post Graduate Institute of Medicine). The faculty of dental sciences will have to negotiate with the ministry of health for graduates of this proposed masters degree scheduled to be offered via the dental faculty (if this degree is offered - it is not offered yet) to be promoted to their grade 1 position in the ministry of health or similar positions in the armed forces and police dental core.

Within the administrative framework and professional culture in Sri Lanka, the best way to introduce a post graduate program in forensic dentistry is through the PGIM. After having realized the context and the current need for a post graduate training program in forensic dentistry in Sri Lanka through the PGIM, a special subcommittee was appointed by the Director/ PGIM with the initiation and recommendations by both board of study $(\mathrm{B} / \mathrm{S})$ dental surgery and $\mathrm{B} / \mathrm{S}$ forensic medicine at PGIM to develop a suitable post graduate program in forensic dentistry towards board certification as specialists. I was appointed as the convener of this special committee formulated by the PGIM in which there were three other members nominated by the Board of Study, Dental Surgery and Board of Study in Forensic Medicine at PGIM. A post graduate diploma program and a doctoral level (MD) program in forensic dentistry which was developed by me after having perused almost all international curricula was proposed to this special subcommittee and it was approved by this special committee with some constructive suggestions. Subsequently this curriculum was approved by both boards of study in Dental Surgery and Forensic Medicine at the PGIM. It is my hope that this program will come out as a successful program in the year 2013 .

My personal estimate is that in 15 years time since inception of this PGIM program, at least 10 specialists (who obtain MD and board certification) need to be trained for the nine provinces (one for each province) with two based in Colombo. Those who obtain the post graduate diploma may work at senior house officer level (in grade 1 position) in the ministry of health or in parallel positions in military departments and contribute their services. The faculty of dental sciences may continue with their master degree program in parallel for those who are interested especially for foreign candidates.

The PGIM may have to revise the curriculum in time to time and decide as to how many trainees required to be recruited given the true need, workload and the demand.

With the proposed post graduate training program, not only the forensic dental service function will be effectively established but also the research outcomes, policy and practice changes, necessary for forensic dental practice will be created in addition to Sri Lanka being an international centre for forensic odontology training for the region.

As forensic medicine and other dental specialties such as maxillo - facial surgery, 
restorative dentistry orthodontics, oral pathology, community dentistry are well developed and highly established disciplines, specialists of those disciplines have to actively help and promote to develop this neglected subspecialty. Fortunately, both the forensic medical profession, PGIM and the dental profession have supported the proposed forensic dentistry post graduate training program though out, which is commendable.

I am sure and optimistic that forensic dentistry will have a prosperous future in Sri Lanka with the blessings of the forensic medical profession, dental profession, legal profession, criminal justice system and the public.

\section{Dr. Induwara Goonerathne}

Editor / Sri Lanka Journal of Forensic Medicine Science and Law

Senior Lecturer, Department of Forensic Medicine \&

Visiting Senior Lecturer and Examiner in Forensic Dentistry and Ethics

Faculty of Dental Sciences

University of Peradeniya. 